Brit. J. industr. Med., 1954, 11, 186.

\title{
THE TREATMENT OF COMPLICATED PNEUMOCONIOSIS WITH ISONIAZID
}

\author{
BY \\ W. E. MIALL, P. D. OLDHAM, and A. L. COCHRANE \\ From the Medical Research Council Pneumoconiosis Research Unit, Llandough Hospital, Cardiff
}

(RECEIVED FOR PUBLICATION MARCH 21, 1954)

Work at the Pneumoconiosis Research Unit and elsewhere has shown that complicated pneumoconiosis is relatively common in the mining areas of Wales (Hart and Aslett, 1942 ; Cochrane, Davies, and Fletcher (1951), that it is severely disabling in the later stages (Gilson and Hugh-Jones, in the press) and definitely reduces the expectation of life (Stewart, Davies, Dowsett, Morrell, and Pierce, 1948). Neither change of occupation nor treatment has been shown to alter the course of the disease. On the basis, however, of the considerable evidence that tuberculosis plays a major part in the aetiology of the progressive massive fibrosis (P.M.F.) of complicated pneumoconiosis (Fletcher and Gough, 1950 ; Van Mechelen, 1935) it seemed reasonable to see whether the rate of radiological progression could be influenced by chemotherapy which was known to be effective in the treatment of pulmonary tuberculosis.

A therapeutic trial of this kind presents unusual difficulties. To allow the maximum chance of success it was decided to include only the earlier cases of progressive massive fibrosis, occurring in relatively young men. However, men in this group have few serious symptoms and are in many cases earning high wages in the coal industry. It would therefore not have been justifiable to keep a large number of them in hospital for prolonged treatment unless very encouraging results of a pilot trial on in-patients had been available. On the other hand, a field experiment of streptomycin involving regular injections would have led inevitably to a high lapse rate. We finally decided therefore on a controlled trial using isoniazid. This avoided the administrative difficulties of injections and the toxic side-effects of streptomycin and P.A.S. which might have been serious in working men. As we were going to treat only cases in which the sputum was negative for tuberculosis, it seemed reasonable at the time the trial started, which was immediately isoniazid became available in this country, to proceed without waiting for further knowledge about the risks of drug resistance. The full extent of the problem was not then known.

\section{The Design of the Trial}

The trial was designed to determine whether the administration of isoniazid to cases of early P.M.F. would diminish the radiological progression rate, which was known to be about $12.5 \%$ per annum for all cases, and greatest in early lesions in young men (Pneumoconiosis Research Unit, unpublished data). Accordingly men were selected who were thought likely to show, in the absence of treatment, the most rapid radiological progression ; they were visited at their homes, volunteers were enlisted, and subsequently divided at random into two numerically equal groups, the treated and the controls.

\section{Treatment}

The dosage scheme used by the M.R.C. Tuberculosis Chemotherapy Trials Committee was followed (Medical Research Council, 1953); a dose of 100 $\mathrm{mg}$. of isoniazid was given twice daily for three months to half the men; the remainder received indistinguishable inert tablets. The first three-month course was separated from a second similar course by an interval of four months. Assessment of the progress of the two groups was made five months after the end of this second course.

During each course tablets of $50 \mathrm{mg}$. each were distributed in bottles of 100 , i.e. 25 days' supply, and every man or his wife was visited at least four times during each three-month course. The patient's physician was asked to continue treatment through intercurrent illnesses unless its discontinuation was thought essential.

\section{Selection of Cases}

The basic requirements for all cases before acceptance into the trial were : (1) That they should have early massive fibrosis visible on plain postero- 
anterior films and on tomography. (2) That they were radiographed by this Unit within the previous two years, and at the time of radiography were under the age of 50 years. (3) That their sputum should not be positive for M. tuberculosis. (4) That they should have no other medical condition likely to interfere with the successful completion of the course, e.g., they should have no albuminuria, as isoniazid had been reported to have toxic effects on the kidneys.

Chest radiographs of over $95 \%$ of all miners and ex-miners in one mining valley had been taken in the Rhondda Fach Scheme (Cochrane, Cox, and Jarman, 1952), and, of the total of 6,026 films, 788 showed complicated pneumoconiosis ; 296 of these were of men under the age of 50 with early massive shadows (Categories $\mathrm{A}$ and $\mathrm{B}$, International Classification, Fletcher, 1950). The films of these 296 were re-read and from them were excluded all cases with sharply defined shadows (an appearance thought to be associated with contraction and possibly indicative of a less active or burnt-out phase), all cases with cavitation, and all cases with the characteristic type of chest radiograph associated with rheumatoid arthritis in coal-workers (Caplan, 1953). This left a total of 173 men. The trial was explained to each of these men during a home visit, and 138 of them volunteered to participate. These men formed the group investigated before inclusion in the trial.

\section{Preliminary and Intermediate Investigations}

Before treatment was started, the following investigations were carried out : (a) Postero-anterior chest radiographs were obtained and at least three tomographs taken at $2 \mathrm{~cm}$. intervals, routinely at 8 , 10 , and $12 \mathrm{~cm}$., with further cuts when indicated. $(b)$ Two laryngeal swabs were taken from each man. (c) The erythrocyte sedimentation rate was determined by the Westergren method. (d) The Middlebrook-Dubos agglutination test was performed (Middlebrook and Dubos, 1948; Scott and Smith, 1950). (e) Each man was weighed. ( $f$ ) Urine specimens were tested for protein.

Urine examinations were repeated after one month's treatment, at the end of the first course, and again at the beginning and end of the second course. All men were weighed at the end of the first course and before the second course, and plain posteroanterior chest radiographs were taken again at the start of the second course of treatment. After the preliminary investigations, eight of the 138 volunteers were excluded from the trial, three for absence of confluent opacity on tomography, three for albuminuria, one for mental deficiency, and one for carcinoma of the stomach. These exclusions left
130 men in the trial ; they were divided at random into two numerically equal groups.

\section{Exclusions during the Trial}

In a field trial of this kind, where close supervision is impossible, and the majority of men have few serious symptoms, lapses are inevitable, and a number of men omitted to take tablets during holidays and intercurrent illness. Any single lapse of up to two weeks has been ignored provided treatment thereafter was taken regularly, but a number of men who stopped taking tablets regularly, or failed to complete each course within one month of its intended date of completion, have been excluded from the analysis.

The final analysis was made on 101 of the 130 volunteers, 52 of the 65 treated, and 49 of the 65 controls. The groups were compared for various characteristics none of which showed any material differences between the groups at the start of the trial, although the treated group was rather lighter in weight than the controls (means 134 and $139 \mathrm{lb}$. respectively). This difference is, however, less than its standard error. The mean ages of men in these two groups at the start of the trial were 42.1 years (range $27 \cdot 5-51 \cdot 3$ years) and 42.3 years (range $29 \cdot 4-$ $51 \cdot 1$ years) respectively. Lapses were greater among the treated than among the controls during the first course, but were twice as great among the controls during the second course. However, none of the differences is greater than could be attributed to chance. The reasons for discontinuing treatment are shown in Table 1.

TABLE 1

REASONS FOR DISCONTINUING TREATMENT IN SUBJECTS EXCLUDED DURING THE TRIAL

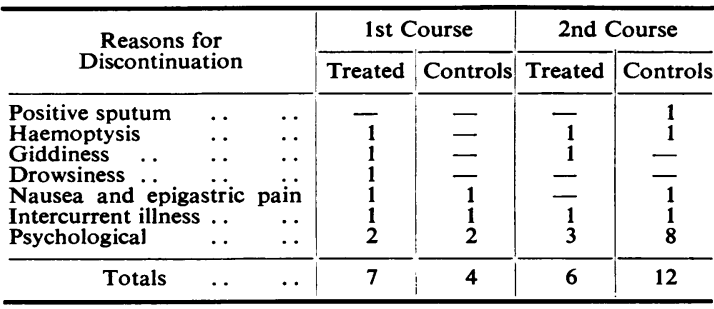

Final Investigations and Assessment

The final investigations were carried out 16 months after the preliminary investigations, and included all the tests except the E.S.R. and Middlebrook-Dubos agglutination test which were done originally only to determine whether they had any prognostic significance. 
The initial and final chest radiographs were read separately by two pairs of physicians who were unaware of the treatment given to each man. Tomograms were used for confirmation when any reader considered progression to have occurred, but where the plain films showed no progression, tomograms were ignored; when doubtful progression read on plain films was not confirmed on tomography, no change was recorded; there remained a small number of cases, however, in which a final reading of doubtful progression was thought essential. There were 23 films in which there was disagreement between the two pairs of readers ; these were read again in consultation and an agreed decision was reached for each film.

\section{Results}

$X$-ray Changes. - The $x$-ray changes between initial and final films of the two groups are shown in Table 2. The differences in the proportions pro-

TABLE 2

RADIOLOGICAL CHANGES IN TREATED AND CONTROL GROUPS AT END OF TRIAL*

\begin{tabular}{l|c|c|c|c}
\hline & Progression & ? Progression & No Change & Total \\
\hline Treated & $8(15 \%)$ & $3(6 \%)$ & $41(79 \%)$ & $52(100 \%)$ \\
Controls & $10(20 \%)$ & $5(10 \%)$ & $35(70 \%)$ & $50(100 \%)$ \\
\hline
\end{tabular}

Grouping "Progression" and "? Progression," $\chi^{2}=0.636$ for 1 degree of freedom, $\mathrm{P}=0.425$.

*One control subject who developed a positive sputum and was thereafter excluded has been included here as a progressor.

gressing are not statistically significant. This Table includes one control who developed positive sputum and was thereafter excluded from the trial; a chest radiograph taken after the completion of the first course of isoniazid had also shown progression.

An attempt was made to determine in which interval the progression had taken place but this was found to be too difficult. Table 3 shows the interobserver error in the initial readings for progression. The extent of the error is somewhat larger than was expected from our experience, based on repeated surveys at collieries, but the interval between the two radiographs was in this case shorter. It is also probably true that the use of tomographs increased the differences between observers. Yerushalmy and others (1951) investigated the inter-observer error in reading progression and regression in cases of pulmonary tuberculosis and found that it was very much larger than their measurements of error in straightforward diagnosis had led them to expect.

Weight Changes.-Both groups increased in weight throughout the trial, the treated group by $2 \cdot 7$
TABLE 3

AGREEMENT BETWEEN TWO PAIRS OF READERS ON X-RAY CHANGES AT END OF TRIAL Readers $\mathbf{C}$ and $\mathrm{D}$

\begin{tabular}{|c|c|c|c|c|}
\hline & $\begin{array}{l}\text { Definite } \\
\text { Pro- } \\
\text { gression }\end{array}$ & $\begin{array}{c}\text { ? Pro- } \\
\text { gression }\end{array}$ & $\begin{array}{c}\text { No } \\
\text { Change }\end{array}$ & $\begin{array}{l}\text { Agreement } \\
\text { of Readers } \\
C \text { and D with } \\
A \text { and } B\end{array}$ \\
\hline $\begin{array}{c}\text { Definite } \\
\text { Progression }\end{array}$ & 9 & 3 & 6 & $9 / 18(50 \%)$ \\
\hline$\stackrel{?}{\text { Progression }}$ & 1 & 2 & 3 & $2 / 6(33 \%)$ \\
\hline $\begin{array}{l}\text { No } \\
\text { Change }\end{array}$ & 6 & 4 & 67 & $67 / 77(87 \%)$ \\
\hline $\begin{array}{c}\text { Agreement } \\
\text { of readers } \\
A \text { and } B \text { with } \\
C \text { and D }\end{array}$ & $9 / 16(56 \%)$ & $2 / 9(22 \%)$ & $67 / 76(88 \%)$ & 101 \\
\hline
\end{tabular}

lb. on the average, the controls by $1.8 \mathrm{lb}$. A detailed analysis of the 49 controls and 49 of the treated group, chosen at random from the full 52 to simplify the statistical analysis, showed no evidence of heterogeneous weight changes among individual men, nor of any significant difference between treated and controls. If the weight changes are expressed as a linear regression on time of weighing, this can be expressed as a gain of $0 \cdot 12 \mathrm{lb}$. per month.

Other Changes.-Subjective assessment of symptoms showed no significant difference between the two groups at the completion of the trial. There were no deaths from pneumoconiosis in either group ; one man in the control group had a series of melanoptyses three weeks after finishing the first course of tablets and laryngeal swabs gave positive evidence of M. tuberculosis.

Haemoptysis is a remarkably common symptom in complicated pneumoconiosis; seven of the 52 treated cases had at least one haemoptysis, and two others had been stopped treatment for persistent haemoptysis and are excluded from the analysis. Four of the 49 controls had a haemoptysis and one other stopped taking tablets on account of this symptom ; 14 of the 130 men ( $11 \%)$, therefore, had at least one haemoptysis during the 16-month period.

Three of the 52 treated cases experienced melanoptysis during the period of the trial as against two of the 49 controls, but two other men in the control group had melanopytsis but are excluded from the analysis for having failed to complete treatment.

Toxic Effects.-In a report on the toxicity of isoniazid, the Committee on Therapy of the American Trudeau Society (1953) estimated toxic reactions in about $5 \%$ of adult patients treated with doses be- 
tween 150 and $300 \mathrm{mg}$. daily ; these were sufficiently severe in $1 \%$ to contraindicate further treatment with the drug.

In this trial toxic effects were not frequently attributable to isoniazid ; treatment was suspended in only two cases, both for persistent haemoptysis, but in neither case was there good evidence that isoniazid was responsible. Two others developed transient albuminuria during the first course of tablets but this did not persist in either case.

Fourteen other men attributed symptoms to isoniazid tablets, including three who discontinued treatment. These symptoms were giddiness (6), disturbances of micturition (2), diarrhoea (2), drowsiness (2), headache (1), and nausea and epigastric pain (1). On the other hand seven of the controls attributed symptoms to the inert tablets as follows : giddiness (3), palpitations (2), haemoptysis (1), and epigastric pain (1).

Progression Related to Occupation.-Previous investigations by the Pneumoconiosis Research Unit had suggested that the progression of complicated pneumoconiosis was independent of dust exposure.

TABLE 4

RADIOLOGICAL CHANGE IN RELATION TO DUST EXPOSURE

\begin{tabular}{l|c|c|c|c}
\hline $\begin{array}{l}\text { Occupational } \\
\text { Environment }\end{array}$ & Progression & $\begin{array}{c}\text { ? Pro- } \\
\text { gression }\end{array}$ & $\begin{array}{c}\text { No } \\
\text { Change }\end{array}$ & Total \\
\cline { 1 - 2 } Dusty 1 & $4(19 \%)$ & $2(10 \%)$ & $15(71 \%)$ & 21 \\
Non-dusty 2 & $13(16 \%)$ & $6(8 \%)$ & $61(76 \%)$ & 80 \\
\hline
\end{tabular}

1. In this group are included colliers, " hard-headers," repairers, packers, conveyor shifters, and hauliers.

2 . In this group are included surface workers, engine drivers, and ex-miners.

Grouping "Progression" and "? Progression," $\chi^{2}=0.029$ for 1 degree of freedom, $0.8<P<0.9$.

In Table 4, the rate of progression of those exposed to dust is compared with those not so exposed ; though the time interval is short, these findings appear to confirm the earlier work; the differences in the proportions progressing are not statistically significant.

Middlebrook-Dubos Agglutination Test.-Only four men in the trial gave a positive result at a titre of 1 in 8 , a result which, by the method used, is said to be comparable with the findings in a control group of healthy non-tuberculous people (James, personal communication). None of these four showed any radiological progression during the trial, and three of the four had erythrocyte sedimentation rates of $10 \mathrm{~mm}$. in one hour or less; furthermore the test was negative in the one case where the sputum became positive. It would seem therefore that a positive test is probably not indicative of a poor prognosis in complicated pneumoconiosis.

Erythrocyte Sedimentation Rate.-Martin (1948) found that the sedimentation rate had a definite prognostic value in complicated pneumoconiosis ; the importance of his findings is somewhat diminished by the fact that $50 \%$ of his whole group died within two years, as this means his original group was very highly selected. Our findings in Table 5 confirm and

TABLE 5

RADIOLOGICAL CHANGE IN RELATION TO E.S.R.

\begin{tabular}{c|c|c|c|c|c}
\hline $\begin{array}{c}\text { E.S.R. } \\
\left(\begin{array}{c}\text { Westergren } \\
(\mathrm{mm} . / 1 \mathrm{hr} .)\end{array}\right.\end{array}$ & $\begin{array}{c}\text { Progres- } \\
\text { sion }\end{array}$ & $\begin{array}{c}\text { ? Progres- } \\
\text { sion }\end{array}$ & \multicolumn{1}{|c|}{$\begin{array}{c}\text { No } \\
\text { Change }\end{array}$} & Total \\
\cline { 2 - 5 } & No. & \multicolumn{1}{|c|}{ No. } & No. & No. \\
\hline $0-$ & $6(9.0 \%)$ & $7(10.4 \%)$ & $54(80.6 \%)$ & $67(100 \%)$ \\
$10-$ & $6(28.6 \%)$ & 0 & $15(71.4 \%)$ & $21(100 \%)$ \\
$20+$ & $5(38.4 \%)$ & $1(7.8 \%)$ & $7(53.8 \%)$ & $13(100 \%)$ \\
\hline
\end{tabular}

extend the observations by Stewart and others (1948) that the E.S.R. has some prognostic value in P.M.F. in that the proportion showing definite or ? progression increases with increasing sedimentation rate, but analysis of the results grouped as in Table 6

TABLE 6

ANALYSIS OF DATA OF TABLE 5

\begin{tabular}{c|c|c|c}
\hline $\begin{array}{c}\text { E.S.R. } \\
\begin{array}{c}\text { (Westergren) } \\
(\mathrm{mm} . / 1 \mathrm{hr} .)\end{array}\end{array}$ & $\begin{array}{c}\text { Progression } \\
\text { and } \\
\text { ? Progression }\end{array}$ & $\begin{array}{c}\text { No } \\
\text { Change }\end{array}$ & Total \\
\cline { 1 - 2 } \cline { 2 - 3 } $10-$ & $13(19 \cdot 4 \%)$ & $54(80 \cdot 6 \%)$ & $67(100 \%)$ \\
$10+$ & $12(35 \cdot 3 \%)$ & $22(64 \cdot 7 \%)$ & $34(100 \%)$ \\
\hline Total & $25(24 \cdot 8 \%)$ & $76(75 \cdot 2 \%)$ & $101(100 \%)$ \\
\hline & $x^{2}=2 \cdot 264 \quad 0.1<\mathrm{P}<0.2$
\end{tabular}

shows no statistically significant effect, and analysis of those with a raised E.S.R. $(10 \mathrm{~mm}$. in one hour or more) indicates (Table 7) that even amongst these cases we still have no means of altering the course of the disease, so the value of a test which tells us that one man is more likely to progress than another is rather limited.

TABLE 7

RADIOLOGICAL CHANGE IN SUBJECTS WITH RAISED E.S.R. (10 MM./1 HR. OR MORE)

\begin{tabular}{|c|c|c|c|c|c|}
\hline & & $\begin{array}{c}\text { Progres- } \\
\text { sion }\end{array}$ & $\begin{array}{c}\text { Progres- } \\
\text { sion }\end{array}$ & $\begin{array}{c}\text { No } \\
\text { Change }\end{array}$ & Total \\
\hline$\overline{\text { Treated } \quad . .}$ & $\ldots$ & 5 & 1 & 11 & 17 \\
\hline Controls & .. & 6 & - & 11 & 17 \\
\hline
\end{tabular}




\section{Discussion}

The trial shows that isoniazid is not dramatically effective in treating cases of early massive fibrosis with negative sputum, but it should be stressed that it may well be of value in cases with positive sputum. No single significant difference appeared in the progress of the treated and control groups, but it is important to remember that, just as successful results may occasionally occur through the play of chance alone, so also may a real effect be obscured in one trial by a combination of chance effects. Fig. 1 represents, in respect of progression rates, what the trial can be claimed to have shown with reasonable certainty (the method used to derive this figure is given as an appendix). In this figure different progression rates in controls and treated are plotted against each other; the observed result, $21 \%$ showing definite or ? progression among the treated subjects, $30 \%$ among the controls, is plotted as a cross. The true effect of isoniazid may be asserted to be within the curved zone surrounding the cross ; the boundary of this zone defines pairs of progression

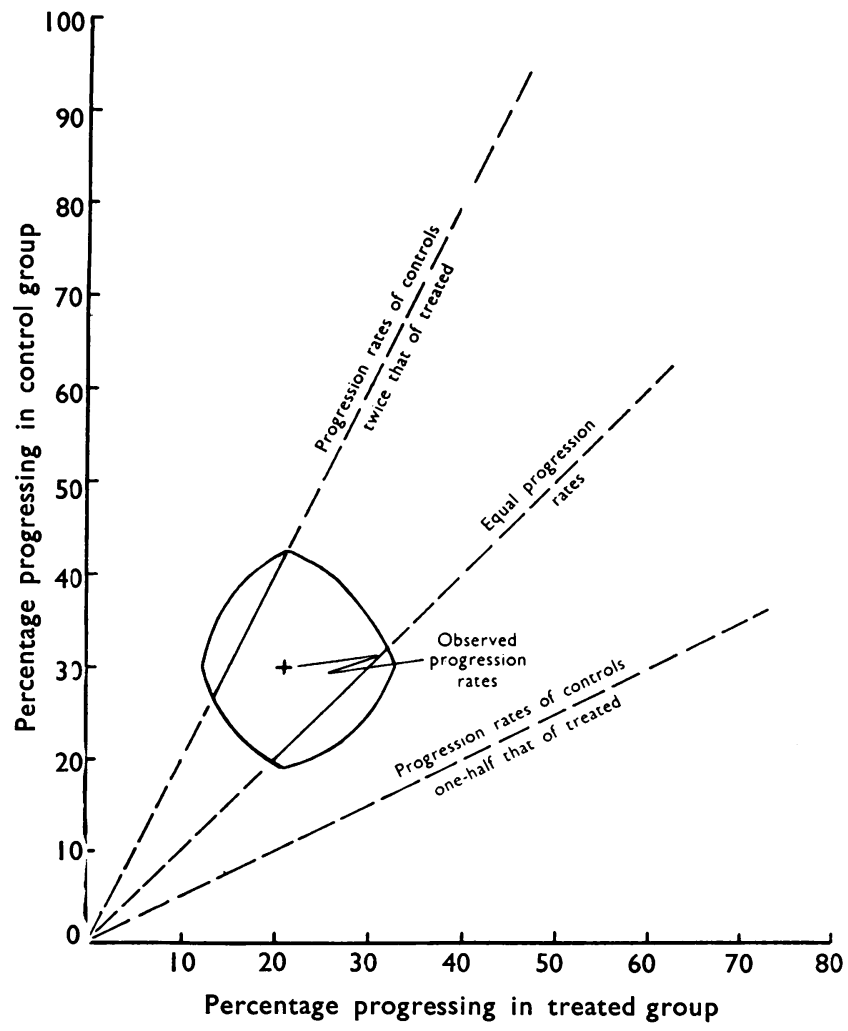

FIG. 1.-Chart showing combinations of progress rates which are compatible (probability greater than 5\%) with results observed in trial. rates which just differ significantly (at the $5 \%$ level) from the observed pairs. If it is said, for example, that a $30 \%$ natural progression rate is reduced to $10 \%$ in the treated group, then the probability of observing the results of this trial is less than $5 \%$ (since the $30-10$ point lies outside the curved zone) and this statement may be rejected as incorrect at the $5 \%$ significance level. However, within the curved zone, a large range of different results is possible. For instance, the line connecting all equal progression rates passes through the zone ; more important, so does the line connecting all points giving twice the progression rate to the controls than to the treated. We cannot claim, for instance, that a $40 \%$ progression rate in the controls and a $20 \%$ one in the treated has been ruled out by the trial results. Only by extending the trial for longer, or by including more subjects, can the range of different but concordant results be reduced.

For the present, it is perhaps reasonable to discuss the implications of the present results as if they were absolute and completely negative. It could then be argued that the lack of success of the trial was evidence against the hypothesis that tuberculosis was a factor in the aetiology of P.M.F.; when massive fibrosis becomes visible on the $x$-ray plate it is probably already a fairly fibrotic lesion, and, on the analogy with chronic fibrotic tuberculosis, we did not expect any marked radiological regression, but it is difficult to reconcile the fact that isoniazid completely failed to influence the progression of existing lesions and the development of new ones with the tuberculosis hypothesis. Similarly, if tuberculous toxicity contributed to the ill health felt by men with massive fibrosis, it might be expected that isoniazid would have caused a significant weight gain in the treated group.

A positive result with isoniazid would, we think, have been strong evidence in support of the tuberculosis hypothesis, but because the disease, if tuberculous, is a form of tuberculosis very modified by the presence of coal dust a negative result is less convincing evidence opposing it.

\section{Summary}

One hundred and thirty coal miners, all under the age of 52 , with early complicated pneumoconiosis and sputum negative for tubercle bacilli, were divided randomly into " treated" and " control " groups in a trial of the effects of isoniazid in this disease. 
Isoniazid, $200 \mathrm{mg}$., was given daily to the treated in two three-monthly courses at home.

The results were assessed in the 101 men who completed both courses and in one man who had developed a positive sputum at the end of 16 months. Amongst the 102 men definite or suggestive radiological progression occurred in $21 \%$ of the treated, $30 \%$ of the controls, but the difference is not statistically significant.

The trial showed no evidence that isoniazid has any dramatic effect in these cases, but the relative insensitivity of the trial did not exclude results compatible with some effect, the limits of which are discussed.

No serious complications or resistant tubercle bacilli were encountered.

We wish to record our thanks to Dr. J. C. Gilson, the Director, and our other colleagues in the Pneumoconiosis Research Unit for valuable advice and criticism, and to the Unit's field survey team who undertook much of the work involved.

Drs. J. Glyn Cox and H. M. Foreman gave helpful advice throughout the trials, and Drs. C. M. Fletcher, J. C. Gilson, and G. S. Kilpatrick kindly assisted in the reading of the films. Drs. Scott Thomson and J. Marks were responsible for the bacteriological investigations, and Drs. Geraint James and F. O'Grady carried out the Middlebrook-Dubos tests. The trial required an exceptionally high standard of radiography and this was achieved by Mr. W. G. Clarke and Mr. J. Chambers.

To all these we gratefully acknowledge our indebtedness and to the miners whose willing cooperation made the trial possible.

Isoniazid (as " rimifon") and dummy tablets were kindly supplied by Roche Products Limited.

\section{REFERENCES}

American Trudeau Society (1953). Amer. Rev. Tuberc., 68, 302. Caplan, A. (1953). Thorax, 8, 29.

Cochrane, A. L., Cox, J. G., and Jarman, T. F. (1952). Brit. med. J., $2,843$.

Davies, I., and Fletcher, C. M. (1951). British Journal of Industrial Medicine, 8, 244.
Fletcher, C. M. (1950). Proc. 3rd International Conference of Experts on Pneumoconiosis. Sydney, 1950, vol. i, p. 104. (I.L.O. Geneva, 1953).

Til, and Gough, J. (1950). Brit. med. Bull., 7, 42.

Gilson, J. C., and Hugh-Jones, P. (1954). In the press.

Hart, P. D'Arcy, and Aslett, E. A. (1942). Spec. Rep. Ser. med. Res. Coun. Lond., No. 243 .

Martin, E. (1948)., Arch. Mal. prof., 9, 104

Medical Research Council, 5th Report of the Tuberculosis Chemotherapy Trials Committee (1953). Brit. med. J., 2, 1005.

Middlebrook, G., and Dubos, R. J. (1948). J. exp. Med., 88, 521.

Scott, N. B., and Smith, D. T. (1950). J. Lab. clin. Med.. 35, 303.

Stewart, A., Davies, I., Dowsett, L., Morrell, F. H., and Pierce, J. W. (1948). British Journal of Industrial Medicine, $5,120$.

Van Mechelen, V. (1935). Verh. kon. Acad. Geneesk. Belg., 15, 281.

Yerushalmy, J., Garland, L. H., Harkness, J. T., Hinshaw, H. C Miller, E. R., Shipman, S. J., and Zwerling, H. B. (1951), Amer. Rev. Tuberc., 64, 225 .

\section{A P P E N D I X}

\section{Note on the Method Used to Derive Figure 1}

If $p_{1}$ and $p_{2}$ are the true progression rates among the treated and control subjects respectively, the chance of obtaining 11 or more progressors among the 52 treated subjects studied is :

$$
\begin{gathered}
\left(\begin{array}{l}
52 \\
11
\end{array}\right) \mathrm{p}_{1}{ }^{11}\left(1-\mathrm{p}_{1}\right)^{41}+\left(\begin{array}{l}
52 \\
12
\end{array}\right) \mathrm{p}_{1}{ }^{12}\left(1-\mathrm{p}_{1}\right)^{40}+\ldots \\
\ldots \ldots+\mathrm{p}_{1}{ }^{52}=\mathrm{I}_{\mathrm{p}_{1}}\left(11_{1} 42\right)
\end{gathered}
$$

where $I_{\mathbf{X}}(p, q)$ is the incomplete B-function ratio :

$$
\int_{0}^{x} x^{p-1}(1-x)^{q-1} d x \div \int_{0}^{1} x^{p-1}(1-x)^{q-1} d x
$$

Similarly, the chance of obtaining 11 or less progressors is $I_{1-p_{1}}(41,12)$. The corresponding probabilities in the control group are $I_{p_{2}}(15,36)$ and $I_{1-p_{2}}(35,16)$.

The joint probability of the two independent samples or of more extreme ones can thus be written down at once in the form of products of two incomplete B-function ratios, and the limits of the values of $p_{1}$ and $p_{2}$ can be derived as those which make the product just less than 0.05 . They can quickly be obtained by means of Pearson's tables (1934).

\section{REFERENCE}

Pearson, K. (1934). Tables of the Incomplete Beta-Function. Biometrika, London. 